\title{
"Para que o jangadeiro, quando morrer, não necessite da caridade pública": Mestre Jerônimo e os direitos sociais na cultura política jangadeira
}

\author{
Berenice Abreu*
}

Resumo: este artigo discute a luta de jangadeiros do Ceará por direitos sociais no final dos anos de 1940 e início da década de 1950. Para pressionar o governo federal pelo cumprimento de promessas feitas por ocasião da viagem de jangada de 1941, os jangadeiros do Ceará desenvolveram várias estratégias de ação, como a divulgação por setores da imprensa brasileira (que assumiu apoiar a luta desses homens pobres, divulgando fartas matérias sobre a vida, o trabalho, a miséria, o sofrimento e o desamparo a que estavam submetidos), a criação de um sindicato, além das constantes viagens das lideranças dos pescadores à capital da República. Como reforço a essas estratégias, mais uma vez, jangadeiros partiram do Ceará em 1951 e chamaram a atenção do Brasil para seus problemas. O destino, dessa vez, era o Rio Grande do Sul, numa homenagem a Getúlio Vargas. Os direitos sociais a serem "cobrados" apareciam para esses trabalhadores como uma alternativa à caridade pública, uma prática que parecia marcar e amedrontar sua vida.

Palavras-chave: jangadeiros; direitos sociais; caridade pública.

Abstract: this article discusses the fight for social rights of the raftsmen from the State of Ceará in the late 1940 s and early 1950s. To put pressure on the Federal Government for the fulfilment of what it promised during the raft trip of 1941, raftsmen of Ceará develop various strategies of action, as the propagation by the Brazilian press, which takes the struggle of these poormen, disseminating abundant materials on the life, work, misery, suffering and helplessness they were submitted to; the creation of a union, in addition to continuous trips of the fishermen' leaders to the capital of the Republic. To reinforce these strategies, once again, raftsmen left Ceará in 1951 and draw attention from whole Brazil to their problems. The destination this time was Rio Grande do Sul, in a tribute to Getulio Vargas. The

* Professora da Universidade Estadual do Ceará. Doutora em História Social (UFF, 2007). Este artigo é resultado do estágio pós-doutoral no CPDOC/FGV, em 2013, sob supervisão da Profa. Ângela de Castro Gomes, com apoio do CNPq. 
social rights to be claimed appeared to those workers as an alternative to public charity, a practice that seemed to mark and frighten their lives.

Keywords: raftsmen; social rights; public charity.

\section{O raid da São Pedro: os aprendizados}

A viagem de Jacaré, Jerônimo, Mané Preto e Tatá ao Rio de Janeiro, de jangada, em plena ditadura do Estado Novo, introduziu os jangadeiros cearenses no mundo dos direitos sociais. Além das denúncias sobre as injustiças e irregularidades ocorridas no universo da pesca, eles falaram diretamente ao presidente Vargas, em audiência pública, a vários dos seus ministros e aos jornalistas com quem toparam ao longo da costa brasileira, especialmente no Rio de Janeiro. Contaram sobre a miséria e as necessidades que enfrentavam cotidianamente em terra e no trabalho no mar. A tônica que - compreenderam -, podia ser assumida naquele campo de possibilidades" era a de "pedir direitos", expressa literalmente na fala de Jacaré. ${ }^{2}$

Os dividendos políticos que a repercussão da viagem daqueles quatro trabalhadores rendeu para o Estado Novo de Getúlio Vargas foram muitos. A autorização expressa para que a tal viagem fosse realizada e a série de eventos festivos que esses trabalhadores participaram na capital da República - o que, em uma "ideia imagem utópica", usando a terminologia sugerida por Bronislaw Baczko3, sinalizava para a demonstração da adesão dos trabalhadores brasileiros ao projeto político do estado getulista - dá mostras da postura assumida pelo Estado diante daquele tipo de reivindicação. Para que nada extrapolasse os limites desse ato de "pedir direitos", agentes da Polícia Política de Vargas foram mobilizados para "acompanhar" os jangadeiros durante todo o período em que estiveram no Rio de Janeiro. ${ }^{4}$

Mas parece que os jangadeiros, por seu lado, acharam também que aqueles políticos, de fato, eram "diferentes" daqueles que, no Ceará, os "mandava prender" quando denunciavam alguma coisa e, de fato, se interessavam pelos problemas dos trabalhadores brasileiros. Não era época de eleição, pois nesse período estavam acostumados a ver os candidatos na beira da praia, com fartos sorrisos, prometendo tudo aos pescadores. Os discursos e as práticas que valorizavam a figura do trabalhador e a esfera do trabalho pareciam ir ao encontro daqueles sujeitos que se viram inseridos positivamente, pela primeira vez, na política oficial. ${ }^{5}$

Além desses ensinamentos, destaquei em meu livro Jangadeiros: uma corajosa jornada em busca de direitos no Estado Novo (cf. nota 3), o aprendizado de

1 VELHO, Gilberto. Projeto e Metamorfose: antropologia das sociedades complexas. 2. ed. Rio de Janeiro: Jorge Zahar, 1999.

2 Para uma análise mais detalhada dessa viagem: ABREU, Berenice. Jangadeiros: uma corajosa jornada em busca de direitos no Estado Novo. Rio de Janeiro: Civilização Brasileira, 2012.

3 BACZKO, Bronislaw. "Imaginação Social”, ENCICLOPÉDIA EINAUDI, v. 5, "Antropos-Homem". Lisboa: Imprensa Nacional/Casa da Moeda, 1985.

4 Ofício $n^{\circ}$. 165, do Diretor do Departamento Nacional do Trabalho, Luiz Augusto do Rêgo Monteiro, ao chefe da Polícia Civil do Rio de Janeiro, Filinto Müller, em 1 de novembro de 1941. Arquivo do Estado do Rio de Janeiro: Fundo Polícia Política, setor Estados - Ceará.

5 Maria Helena Capelato sugere que a introdução dos direitos trabalhistas no Brasil alterou as "sensibilidades", no sentido de que os trabalhadores se sentiram parte, sujeitos da História. CAPELATO, Maria Helena R. Multidões em cena: propaganda política no varguismo e no peronismo. Campinas: Papirus, 1998, p. 247. 
classe que a viagem ao longo do litoral proporcionou aos jangadeiros da jangada São Pedro. Falando ao presidente Vargas, Jacaré revelou que, quando saiu do Ceará, pensava em falar apenas em nome dos companheiros do seu estado, mas, ao travar contato com os "irmãos de palhoça e de sofrimento" até a capital da República, compreendeu que deveria falar em nome dos pescadores de todo o "Norte".

Mas há, ainda, outro aprendizado, também imprevisível, que resultou da experiência da viagem de 1941. Refiro-me ao reconhecimento dos limites do recurso à ampla rede paternalista e de caridade pública por parte dos jangadeiros, especialmente por Jerônimo André de Souza, o mestre da jangada São Pedro, que assumirá forte liderança entre os jangadeiros do Ceará e ainda realizará mais duas viagens, de jangada, com fins de denúncia e reivindicação. Por ocasião da viagem da São Pedro e com a ajuda de setores da imprensa brasileira, uma ampla e bem sucedida campanha foi movida para levantar fundos para os pescadores e suas famílias. Os desentendimentos em torno da utilização do arrecadado levaram, entretanto, esses pescadores a conflitos com antigos padrinhos e a reações inflamadas de ambos os lados.

O que os jangadeiros "do Norte" conseguiram efetivamente, além desses aprendizados, parecia apontar para mudanças significativas na vida desses trabalhadores. Com a assinatura do Decreto $\mathrm{n}^{\circ}$. 3.832, de 18 de dezembro de 1941, os pescadores foram associados ao Instituto de Aposentadoria e Pensão dos Marítimos, tornando-se beneficiários dos direitos sociais conquistados por aquela categoria. Jacaré, ao saber da assinatura dessa lei, disse a um jornalista, desconfiado: "Se essa lei for cumprida, vai ser um colosso". Na praia de Iracema, em Fortaleza, outro jangadeiro, falando ao jornalista sobre a tal medida legal, disse que aquilo era igual a Lei Áurea, libertando os jangadeiros da escravidão.

Jacaré lutou todo o tempo que se seguiu ao encontro com Vargas pelo cumprimento do tal decreto; ainda falou ao presidente mais uma vez, por meio de telegrama, denunciando o descumprimento local de suas "ordens". A morte trágica desse pescador nas águas da Barra da Tijuca, seis meses depois da assinatura do decreto, quando representava ele próprio para as lentes de Orson Welles, entretanto, não silenciou os ecos dos trabalhadores do mar. Um novo "lobo do mar” surgia dos verdes mares bravios do Ceará, era Jerônimo André de Souza, o mestre da São Pedro, que deu prosseguimento à luta dos jangadeiros, não mais "pedindo", mas cobrando os “direitos" prometidos pelo estado getulista.

\section{Mestre Jerônimo André de Souza}

Jerônimo veio para Fortaleza por intermédio do primo mais velho, Tatá, também proveniente da cidade litorânea de Uruaú. Na praia de Iracema, segundo dona Celsa Gomes, viúva de Tatá, parece ter trabalhado inicialmente com Fernando Pinto, dono do Jangada Club, um amigo dos jangadeiros que prestou grande apoio e incentivo à viagem realizada em 1941. Não se sabe exatamente quando passou a trabalhar como pescador, mas há versões de que Jerônimo não se sentia atraído pelo trabalho no mar. Bernardo Doré descreve do seguinte modo a iniciação do mestre no universo da pesca: 
com relutância que trepara para o "bote" do pai aos dez anos, e se fora com ele para a "risca". Achava aquilo um brinquedo de pouca monta... Quando viu, porém, de perto, os riscos da pescaria, se sentiu cheio de orgulho. Jamais lhe saíram da lembrança as primeiras horas passadas em alto mar. No dia em que Ihe deram a roupa engrossada com tinta de cajueiro, foi como se lhe tivessem dado o diploma de homem. Ficou cheio de si! ${ }^{6}$

Também Dona Celsa Gomes me contou que ouvia de Tatá umas histórias de que Jerônimo não queria ir ao mar com os mais velhos, alegando que o balanço das ondas lhe causava fortes enjoos. Os parentes ameaçaram-no dizendo que, se ele continuasse se recusando, iriam amarrá-lo no mastro da jangada em alto mar, até ele se acostumar. Não teve jeito, o mar, literalmente, seria o habitat natural de Jerônimo, tanto na vida, como na morte. ${ }^{7}$

Já com roupa "engrossada com tinta de cajueiro", Jerônimo assumiu o trabalho na pesca e filiou-se na Colônia Z-1 e depois na Z-2, praia de Iracema e praia do Mucuripe. Notabilizou-se como mestre de jangada a partir de uma regata (disputa entre jangadas) que venceu, levando a bordo o então magnata das comunicações Assis Chateaubriand. Depois disso, sua fama se desdobrará, como mostrei em trabalho anterior, ${ }^{8}$ com a condução da jangada São Pedro, que chega ao Rio de Janeiro em 15 de Novembro de 1941, e das outras viagens da década de 1950, do que falarei a seguir. ${ }^{9}$

Mestre Jerônimo segue novamente à capital da República em 29 de maio de 1948, sete anos depois do raid da São Pedro e da assinatura do decreto que estendia aos pescadores de todo o Brasil os direitos sociais auferidos pelo Instituto dos Marítimos, ${ }^{10}$ anunciando que as promessas feitas por ocasião daquela viagem "não deram em nada" e que "a ditadura tudo prometeu aos jangadeiros e nada Ihes deu afinal"."11

Complementando o quadro acima descrito, Jerônimo diz ao jornalista da Agência Meridional que os jangadeiros do Ceará "não possuem organização sindical, nem garantias legais, nem amparo técnico, nem coisa nenhuma, tendo suas casas em ruínas, as suas famílias passando fome, as suas redes rasgadas, as suas jangadas cheias de avarias". Sintetizando as demandas da categoria e a retomada da luta em prol dos jangadeiros, Jerônimo fala da intenção de fundar e dirigir o próprio sindicato, "lutar pela elevação do processo de trabalho" e "organizar enfim a classe para que o jangadeiro quando morrer não necessite da caridade pública para fazer o seu enterro". Apesar da frustração expressa nas palavras/desabafos do jangadeiro, ele revela ainda ter "esperanças". ${ }^{12}$

Durante as décadas de 1940 e 1950, o mestre da jangada São Pedro assume a voz dos jangadeiros e empreende uma luta por aquilo que entendia serem os direitos da categoria. Essa "luta" era empreendida através do recurso à imprensa, do contato com autoridades políticas e ainda, mais uma vez, de viagens de jangadas, com destinos ainda mais ambiciosos: Porto Alegre e Buenos Aires.

6 DORÉ, Bernardo. A epopeia dos jangadeiros, nossos irmãos do mar. Fortaleza: Edição do autor, 1973, pp. 22-23. Nesse romance, o autor tem como personagens centrais os quatro pescadores do raid de 1941.

7 Entrevista com dona Celsa Gomes, em 2001 e 2003, em sua residência.

8 ABREU. Jangadeiros.

9 Luís da Câmara Cascudo cita Jerônimo como realizador do raid. CASCUDO, Luís da Câmara. Jangada: uma pesquisa etnográfica. 2. ed. São Paulo: Global, 2002.

10 VARGAS, Getúlio. Diário. São Paulo: Siciliano [s.d.]; Rio de Janeiro: Fundação Getúlio Vargas, 1995, p. 436.

11 O jornal Unitário, de Fortaleza, em 29 de maio de 1948, na página 1, reproduz, da Agência Meridional, essa reportagem com mestre Jerônimo.

12 Jornal Unitário, Fortaleza, 29 de maio de 1948, p. 1. 
Este artigo discutirá a cultura política dos jangadeiros, simbolizada nas ações de denúncia e reivindicação de direitos sociais, enfocando a passagem de um comportamento marcado pela recorrência à caridade pública para o recurso ao universo dos direitos sociais. Puxando o fio da discussão estará Jerônimo e suas ações de resistência e luta; ao lado dele, outros sujeitos que engrossarão o coro na luta por direitos.

A partir de um cotidiano de vida marcado pela precariedade material - a miséria da qual falava -, e dos riscos constantes vivenciados no trabalho - a pesca de jangada realizada no mar -, Jerônimo e seus companheiros vislumbravam esses direitos como uma alternativa à caridade pública, que marcava o cotidiano desses trabalhadores pobres, e à dependência que tinham do proprietário da embarcação na qual trabalhavam, a quem tinham que entregar metade do produto da pesca.

Nas páginas a seguir, retomarei aspectos da vivência de Jerônimo e seus companheiros, discutindo a cultura política dos jangadeiros, marcada pelas lutas em prol da organização da classe, pelo enfrentamento dos riscos do trabalho no mar; do fantasma da morte que ronda os protagonistas e suas famílias e do drama da recorrência às autoridades a fim de sepultar os mortos e amparar viúvas e órfãos; pelo recurso à imprensa de todo o Brasil para amplificar as suas vozes de denúncia e reivindicação e pelos aprendizados das viagens, inclusive as de jangada com fins de denúncia e reivindicação.

\section{Em meio à luta, o descumprimento do Código de Pesca e o processo por deserção}

Quando Jerônimo retorna ao Ceará, em 1948, retoma a mobilização dos trabalhadores do mar para a luta pelo cumprimento das promessas por direitos sociais, e funda, segundo conta ao jornalista do Unitário,"13 "uma espécie de sindicato", ${ }^{14}$ a fim de aplicar a verba prometida pelo governo Dutra, na última viagem que fez ao Rio de Janeiro. Mas o fato que o leva a novamente bater às portas da imprensa e dos "amigos de todos os tempos" eram as ameaças que se seguiram a essa iniciativa: estava ameaçado de parar de pescar, perder a matrícula de pescador.

Segundo apurou o jornalista do jornal Unitário, de Fortaleza, com o titular da Delegacia de Caça e Pesca no Ceará, Sebastião Ramos, Jerônimo estava de fato sendo processado, juntamente com mais quatro companheiros, por deserção, podendo vir a ser impedido de exercer a profissão de pescador porferir dispositivos do Código de Pesca. Sebastião Ramos insinua ao jornalista que Jerônimo estava "mal orientado" e que vinha influenciando outros companheiros a, como ele próprio, desprezar as Colônias de Pesca, recusando-se a fazer parte delas. Sobre

13 O jornalista e membro do Instituto Histórico do Ceará, Geraldo da Silva Nobre, endossado por outros profissionais que atuaram na imprensa do Ceará nas décadas de 1940 e 1950, como Blanchard Girão, afirmam que o jornal Unitário, juntamente com o Correio do Ceará, operaram um marco na imprensa do estado, sendo os primeiros a assumirem um caráter mais noticioso e informativo, em oposição àqueles mais partidários que então existiam. O Unitário foi incorporado ao grupo dos Diários Associados, de Assis Chateaubriand, em 1940. Sobre isso, conferir: NOBRE, Geraldo da Silva. Introdução à história do Jornalismo Cearense. Fortaleza: Expressão Gráfica, 2006; e PONTE, Sebastião Rogério. História e Memória do Jornalismo Cearense. Fortaleza: Núcleo de Documentação Cultural/NUDOC, 2004.

14 O Sindicato dos Pescadores do Ceará só vai ser reconhecido pelo Ministério do Trabalho Indústria e Comércio em 1953. 
isso, escreve o redator da matéria, assumindo explicitamente a causa do pescador:

Foi-se comentando na redação que a consumação da ameaça seria uma injustiça clamorosa inominável: além do mais, mataria Jerônimo, derrubaria um dos poucos heróis autênticos que ainda possuímos. Essencialmente grotesco ficar um homem como o timoneiro da inesquecível S. Pedro nas grades da vida em terra firme. ${ }^{15}$

De fato, no Código de Pesca, ${ }^{16}$ capítulo II: dos Pescadores e suas Associações de Classe, artigo $8^{\circ}$, estava prescrito que "todo pescador profissional é obrigado a fazer parte da colônia em cuja zona resida". Jerônimo argumentou em seu favor que as Colônias Z-1 e Z-2, respectivamente das praias de Iracema e de Mucuripe, estavam fechadas há tempos, reabertas de última hora, e foram realizadas eleições que sufragaram nomes de pessoas que já haviam cometido desfalque no passado e que não representavam os interesses da classe. Por isso "fugiu desesperadamente" da colônia e foi fundar sua "espécie de sindicato", que fora interditado pelo dirigente da delegacia do Ceará.

Essa "espécie de sindicato" aparecia para Jerônimo e para os companheiros rebeldes das praias de Fortaleza como uma alternativa na intermediação da luta dos jangadeiros por direitos e pelo cumprimento do amparo dado pelo Estado aos jangadeiros. A crença na colônia, tantas vezes expressa por Jacaré na viagem de 1941, parecia não mais existir entre os praieiros que deram prosseguimento a sua luta. O fato de não poder mais pescar condenava os rebeldes pescadores a ficarem "nas grades da vida em terra firme", como disse o jornalista do Unitário. Essa ideia atormentava Jerônimo, que se perguntava: "Eu morrendo agora, onde é que vão buscar dinheiro, a não ser à custa de esmolas, para me enterrar?"17

Para Jerônimo, a morte no mar o livraria da esmola, da caridade...

\section{O fantasma da morte nada ao lado: as ameaças do mar}

É fato que, nas várias oportunidades em que falou à imprensa, Jerônimo sempre retornava ao tema da morte no mar e no consequente desamparo a que eram deixados viúvas, filhos e agregados dos pescadores. De fato, o trabalho de pesca em jangadas era arriscado e, apesar dos jangadeiros confiarem na embarcação que lhe servia de meio para realizar uma pescaria, ${ }^{18}$ havia sempre que se contar com a imprevisibilidade do vento, com o enfurecimento do mar e ainda com animais marinhos que cercavam as jangadas.

Em outubro de $1949,{ }^{19}$ os jangadeiros Francisco Henrique de Souza, seu

15 Jornal Unitário, Fortaleza, 19 de março de 1949, p. 6.

16 Esse código é aprovado pelo Decreto-Lei nº 794, de 19 de Outubro de 1938.

17 Jornal Unitário, 19 de março de 1949, p. 6.

18 Segundo Câmara Cascudo, por volta dos anos de 1940, no Rio Grande do Norte, surgia a jangada de tábuas, que viria a substituir mais tarde a tradicional jangada de paus, feita de uma madeira adquirida no Pará, Apeiba tibourbou ou pau-de-jangada. Na década de 1950, quando escreveu os seus livros Jangadas e Jangadeiros, Câmara Cascudo sugeria que essas embarcações de tábuas já estavam sendo utilizadas no Ceará; entretanto, o jangadeiro confiava mais na antiga embarcação por sua capacidade de flutuar, socorrendo o jangadeiro na hora de infortúnios. A jangada de tábuas era denominada caixão de defuntos, por que afundava mais facilmente. CASCUDO. Jangada; BRASIL. Jangadeiros. Rio de Janeiro: Ministério da Agricultura/Serviço de Informação Agrícola, 1957.

19 Jornal Unitário, Fortaleza, 08 de outubro de 1949, p. 6. 
filho homônimo, Moisés Celestino, Gabriel Ferreira Lima e Moisés Cândido de Lima foram à redação do jornal Unitário, em Fortaleza, para narrar a aventura que protagonizaram que, por pouco, não terminou em tragédia. Após uma promissora pescaria, quando já se preparavam para retornar à terra, o "bote" 20 em que viajavam, de nome Campina, virou inesperadamente, em virtude de uma forte ventania, que fez o mar se enfurecer. Os jangadeiros foram lançados ao mar, e os peixes, que escaparam por completo do samburá, ${ }^{21}$ atraíram tubarões que cercaram os náufragos por duas horas, enquanto estes tentavam escapar segurando-se nas bordas da embarcação. Quando achavam que tudo estava perdido, avistaram o "bote" Ajudante, tripulado pelo mestre Genésio Martins que, com mais cinco pescadores, resgataram os tripulantes do Campina. O resultado do esforço de um dia e o barco que servia de meio de trabalho foram deixados no mar revolto.

Os jangadeiros da jangada Arapirá, entretanto, não tiveram a mesma sorte. O mestre José Soares Filho e seus companheiros, os jangadeiros José Rodrigues de Sena, Pedro Jorge da Costa, José Raimundo Lima e João Costa de Albuquerque, pescavam a cerca de dez léguas da praia, quando, segundo suspeita o presidente da Colônia de Pesca Z-2 do Mucuripe, Pedro Rodrigues de Sousa, foram tragados pelas ondas do mar e devorados por tubarões. ${ }^{22}$ No dia seguinte à divulgação do desaparecimento dos cinco jangadeiros, o jornal Unitário promove uma campanha a fim de mobilizar a caridade pública para ajudar as viúvas e órfãos daqueles trabalhadores. Ao lado do fantasma da morte, rondava também o da caridade, o fantasma que mais parecia amedrontar mestre Jerônimo.

Ainda em 1949, ${ }^{23}$ o navio cargueiro Rio Solimões, do Lloyd Brasileiro, navegava tranquilamente retornando de Fortaleza, quando, por volta das 18:30h, os tripulantes avistaram um homem agarrado aos paus de uma jangada acenando desesperadamente. Tratava-se do pescador Luiz Doido, que contou que estava pescando sozinho, quando a embarcação virou. Ir sozinho para uma pescaria não parecia prática comum na cultura jangadeira. Câmara Cascudo enfatiza que o jangadeiro, tanto no mar quanto em terra, sempre estava em grupo. Na pescaria, ia em grupos de três, quatro ou cinco pescadores, tendo cada um uma função definida no trabalho da pescaria e na condução da embarcação. Essa prática, do trabalho em grupo, deve-se, principalmente, à necessidade de contar com ajuda em momentos de adversidades, como nesse em que se encontrou Luiz Doido. Cada um dos tripulantes de uma jangada tem uma função específica. No Ceará, os mais comuns na pescaria jangadeira são: mestre, proeiro, rebique e bico-de-proa. ${ }^{24}$

Em 1951, um novo incidente envolvendo jangadeiros é levado ao conhecimento dos jornalistas. O mestre Paulo de Lima e seus três companheiros, Francisco Máximo dos Santos, Luiz Antônio dos Santos e João Guerra, foram surpreendidos quando pescavam além da risca ${ }^{25}$ por uma forte rajada de vento que fez a jangada virar. Três deles contam que, após se debaterem contra as ondas,

20 Apesar de o jornal noticiar que essa embarcação, como a referida logo a seguir, era um bote, imagino que se tratava, na verdade, de um paquete, "uma jangada de seis metros, com um metro e vinte de largura [...] tem todos os aviamentos da jangada grande ou jangada do alto". Um bote só comporta no máximo três homens e não se presta para a pescaria aqui descrita. CASCUDO. Jangada; BRASIL. Jangadeiros. Rio de Janeiro: Ministério da Agricultura/Serviço de Informação Agrícola, 1957.

21 Samburá é uma cesta de palha onde os jangadeiros armazenam os peixes pescados.

22 Jornal Unitário, Fortaleza, 18 de novembro de 1949, p. 8.

23 Jornal Unitário, Fortaleza, 21 de dezembro de 1949, p. 8.

24 CASCUDO, Luís da Câmara. Jangadeiros, Rio de Janeiro: Ministério da Agricultura/Serviço de Informação Agrícola, 1957.

25 A risca se localiza a mais ou menos "30 milhas razoáveis da terra, tendo cerca de 50 metros de fundo [...] caracteriza-a a existência de pedras, cachoupos, recifes submersos, viveiros naturais de pescado". CASCUDO. Jangadeiros, p. 26. 
conseguiram se agarrar à embarcação; João Guerra, porém, ficou preso em uma corda, dentro d'água, e morreu afogado. Os sobreviventes foram socorridos por jangadeiros que pescavam em uma embarcação do mesmo proprietário, Oscar Verçosa. ${ }^{26}$ Segundo o jornalista, por volta das $16 \mathrm{~h}$ de um dia de setembro de 1951, "depois de algumas horas de viagem, os náufragos, conduzindo o companheiro morto, conseguiram chegar ao Mucuripe, arrastando com dificuldade a própria jangada que havia virado em alto mar". ${ }^{27}$

A morte era uma ameaça bem real no cotidiano dos jangadeiros. Jerônimo conhecia de perto essas narrativas e se comoveu com o drama vivido pelas viúvas e filhos que ficaram nas "grades da vida em terra firme" depois da morte de seus provedores. Esse drama, aliás, é o fio condutor que amarra a narrativa fílmica de duas películas contemporâneas da viagem dos jangadeiros da São Pedro, na década de 1940.

A primeira delas, A jangada voltou só, ${ }^{28}$ uma realização de Rui Santos, encomendada pelo Departamento de Imprensa e Propaganda do primeiro governo Vargas (DIP), contava a história de um jangadeiro que, interpretado por Dorival Caymmi, autor da música que dá título ao filme, protagonizava a morte no mar.

A segunda, dirigida por Orson Welles, teve como atores principais os próprios jangadeiros da São Pedro. No episódio Quatro homens em uma jangada, a comunidade pesqueira assiste ao casamento de um jovem jangadeiro, quando, em meio à rotina da pesca e da vida pacata da comunidade, ocorre um acidente com a jangada em que navegava. Após alguns dias, a filha bem pequena do jangadeiro desaparecido avista o corpo do pai boiando a beira-mar e corre para contar à mãe viúva e aos demais o ocorrido. O cortejo fúnebre é reproduzido em cena pungente e bela, tendo à frente e segurando a rede onde é conduzido o morto justamente o mestre Jerônimo. Após esse episódio, os mais velhos da comunidade decidem que é preciso fazer algo e resolvem apoiar a viagem de jangada até a capital federal. ${ }^{29}$

\section{As viagens à capital federal: os protagonistas e seus interlocutores da imprensa}

A viagem de 1941 introduziu os jangadeiros no universo dos direitos sociais e, mesmo com os limites ao pleno cumprimento do decreto presidencial de amparo aos pescadores do Brasil, o certo é que eles aprenderam a recorrer diretamente ao Estado para solucionar problemas relacionados à categoria e para cobrar promessas feitas. Algumas vezes mestre Jerônimo foi diretamente se entender com as autoridades; às vezes, outras lideranças dos pescadores, companheiros seus.

Algo a ser esclarecido desde logo é que as viagens aparecem na imprensa

26 Os jangadeiros, em sua maior parte, não eram os proprietários das jangadas em que trabalhavam. Em 1941, uma das injustiças denunciadas por Jacaré e seus companheiros, dentre eles Jerônimo, era o fato de terem que entregar metade do pescado ao proprietário, enquanto a outra metade era dividida entre os homens que se arriscavam no mar.

27 Jornal Unitário, Fortaleza, 12 de setembro de 1951, última página.

28 Esse filme se constituiu, na verdade, em um cinejornal. SOUZA, J. I. M. "Trabalhando com cinejornais: relato de uma experiência”. História: Questões e Debates. Curitiba: UFPR, n. 38, jan./jun. p. 43-65, 2003.

29 HOLANDA, Firmino. Orson Welles no Ceará. Fortaleza: Edições Demócrito Rocha, 2001; SANTOS, Márcia Juliana. It's All True e as construções das imagens do Brasil (1942-1993). (Dissertação em História Social, PUC/ SP, 2004). 
antes ou durante sua realização. Depreende-se desse fato que, no "projeto" da viagem, se vislumbra o peso da divulgação, sensibilizando os jornalistas e a sociedade para a legitimidade da ação. As matérias combinam, quase sempre, a estratégia de apresentar aspectos curiosos e desconhecidos sobre o trabalho desses pobres trabalhadores no mar, enfrentando o imprevisto e a ferocidade dos animais marinhos e da natureza, e, ao mesmo tempo, de revelar as adversidades vividas em terra firme, a miséria, o desamparo e a exploração.

Em 1940, um ano antes da partida da São Pedro, o jornalista Theophilo de Barros Filho, do Diário da Noite, do Rio de Janeiro, em visita a Fortaleza para conhecer as obras do porto do Mucuripe, encontra Jerônimo e alguns companheiros na praia e fica sabendo da viagem que esse jangadeiro e mais dois companheiros desejavam fazer a bordo do barco à vela Jangadeiro, pertencente a Symour Marwin, da fábrica de óleo vegetal Brasil Oiticica. Nessa primeira notícia, os companheiros de Jerônimo seriam João Marcelino de Moura e José da Rosa. A finalidade, segundo o jornalista, era apenas esportiva, não havendo "nenhuma intenção política", assegurava. Sobre Jerônimo, diz o jornalista:

Caboclo forte, tipo de pescador cearense já acostumado à inconstância do seu verde mar, mestre Jerônimo não é um jangadeiro vulgar. Existe nele uma serenidade, uma convicção que impressiona. Exímio conhecedor dos ventos e hábil manejador de cordas e velas, foi mestre Jerônimo quem manobrou certa vez a jangada vencedora da corrida em homenagem ao Sr. Assis Chateaubriand, quando de sua recente visita ao Ceará. Em competições dessa natureza sua peripécia é respeitada porque ele é amigo íntimo das ondas e conhece todos os segredos da imensa planície líquida. ${ }^{30}$

Mas a viagem que se concretizou em 1941 teve uma forte conotação política. Tendo em vista o contexto da ditadura do Estado Novo, é possível que o jornalista tenha sido cauteloso nas suas descrições sobre as intenções dos jangadeiros, ou também pode ter acontecido que a entrada de Jacaré no grupo tenha conferido mais que um sentido esportivo. Além de Jerônimo e Jacaré, viajaram Mané Preto e Tatá, composição diferente da anunciada na reportagem de 1940. Penso que as duas hipóteses possam estar corretas; entretanto, acredito que o aprendizado político de Jerônimo tenha se iniciado com a convivência com Jacaré e foi fortalecida com o raid da São Pedro.

Em abril de 1950, Jerônimo anuncia no jornal Diários Associados que vai ao Rio de Janeiro, a convite de Carlos Lacerda, para falar com o presidente Dutra e com o ministro da Marinha, a respeito do amparo aos jangadeiros pelo Instituto dos Marítimos. Sendo Lacerda um grande opositor do getulismo, a aproximação com os jangadeiros, ainda desamparados pelo poder público, poderia render bons dividendos para a oposição a Vargas. Antes de viajar, porém, Jerônimo vai à redação daquele jornal agradecer o apoio e se despedir, aproveitando para defender-se de acusações feitas por "alguns elementos". Sem nomear esses elementos nem o teor das acusações, Jerônimo afirma: “- Não temos tempo para política, pois somos homens que nos dedicamos à vida do mar e que não dispomos de tempo para nos ocuparmos de assuntos dessa natureza". ${ }^{31}$

No período posterior à viagem da São Pedro, até o fim da década de 1950, os jangadeiros se viram envolvidos na luta pela efetivação dos direitos sinalizada pela incorporação ao Instituto dos Marítimos e nesse movimento teve destaque

30 Jornal Diário da Noite, Rio de Janeiro, 11 de outubro de 1940, p. 1.

31 Jornal Unitário, Fortaleza, 15 de abril de 1950, p. 5. 
a atuação de Valdemar Falcão, seja como deputado ou como presidente daquele instituto, no governo Dutra. Nos anos de 1940 e 1950, foram enviados ao Ceará funcionários do governo para inscrever os pescadores, fazendo parecer que a promessa iria se concretizar. Porém, o tipo de relação de trabalho a que os jangadeiros estavam submetidos colocava obstáculos para a contribuição de pescadores e donos de jangadas (patrões) ao instituto, o que colocava por terra o usufruto de certos benefícios, como a aposentadoria e a remuneração por enfermidades ou acidentes de trabalho. ${ }^{32}$

Em maio de 1950, era o jangadeiro José Severiano da Silva que falava aos jornalistas dos Diários Associados no Rio de Janeiro,33 apresentado como líder de "mais de 1.500 pescadores". Severiano conta da vida perigosa do pescador no mar, descrevendo com minúcias o momento em que enfrentam a fúria do mar, quando a jangada vira e os pescadores lutam para desvirar a embarcação. Também relata a companhia indesejada de tubarões, que, por vezes, cercam a jangada e expulsam os peixes da área, dificultando assim a pescaria. Sobre os tubarões, o jangadeiro se vale de um protetor, a toninha.

Damos graças a Deus quando aparece uma tuinha. Ela dá combate aos tubarões. É uma luta bonita que a gente assiste da jangada. Os corpos espelhantes, como se fossem de madrepérola, revelam-se na transparência do mar. Rolam sobre si mesmas, espadanam e seguemse rabanadas violentas. Se a tuinha nota que vai perder, porque está sozinha, lutando com muitos tubarões, dá salto alto sobre o mar e um silvo agudo, espécie de assobio, tão conhecido do pescador. É o sinal de alarma, o apito do "policial" marinho. Não tarda muito chegarem as companheiras, às centenas. De repente, em volta da jangada, o mar fica pretinho de tuinhas e a luta recomeça. Fogem os tubarões e nós voltamos à pescaria interrompida. A tuinha é um dos peixes mais velozes do mar.

Por conta dessa parceria com as "tuinhas", Severiano afirma que existe um acordo entre os pescadores de nunca aprisionar esse animal marinho e, caso alguém incorra nessa infração, será "processado" pelos outros, mas, como ele diz, se trata de "um processo a nosso jeito". O outro protetor dos jangadeiros, para o caso das aflições pelo furor vindo da natureza, é São Pedro, padroeiro dos pescadores.

Mas, misturada a essas informações sobre o cotidiano da pesca e as adversidades porque passam os jangadeiros no mar, Severiano conta da miséria em que vivem na terra e denuncia, reafirmando o que já havia feito os pescadores da São Pedro: os donos de jangadas, que exploram os jangadeiros, tirando proveito do fruto do trabalho arriscado no mar, a quem têm que dar metade do pescado; e os atravessadores, que compram o peixe do pescador e revendem por um valor bem mais alto, pagando depois de concluída a venda. Ao final da entrevista, revela que a família de Jacaré, um dos jangadeiros da São Pedro, morto quando das filmagens no Rio de Janeiro, estava passando necessidades em Fortaleza e os juros da indenização paga por Orson Welles eram insuficientes para a manutenção da extensa família, composta de 9 filhos e a viúva. ${ }^{34}$

32 As relações de trabalho entre patrões e jangadeiros eram informais e pouco monetarizadas, caracterizando-se pela divisão do pescado igualmente entre as duas partes - fato sempre denunciado como injusto pelos pescadores.

33 Jornal Diário da Noite, Rio de Janeiro, 30 de maio de 1950, p. 1 e 6.

34 As filhas de Jacaré, Maria, Maria José e Raimunda, descreveram, emocionadas, o estado de isolamento e tristeza que se abateu na família após a morte do pai. A mãe, dona Josefina, entrou em depressão profunda que a levou à morte, passados alguns anos, e foi a filha mais velha, Maria, quem terminou de 
Em julho de 1951, já sob o novo governo Vargas, Jerônimo segue novamente para o Rio de Janeiro, tentando se entender com os ministros da Agricultura, 35 João Cleofas de Oliveira, e do Trabalho, Indústria e Comércio, Danton Coelho. Mais uma vez, recorre aos "amigos de todos os tempos". Antes de ir, ainda em Fortaleza, procura o jornal Unitário, dos Diários Associados, do velho amigo Assis Chateaubriand, e anuncia que viajará para falar com o presidente levando para ele duas reivindicações: a destituição do delegado de Caça e Pesca do Ceará, o Sr. Sebastião Ramos, e autorização para um pescador profissional acompanhar a movimentação financeira da colônia. ${ }^{36}$

Já no Rio de Janeiro, é o amigo Edmar Morel quem faz uma impactante reportagem ${ }^{37}$ sobre a situação enfrentada pelos jangadeiros do Nordeste, cerca de 20.000, segundo dados da divisão de Caça e Pesca, jogados na miséria e vivendo em pobres choupanas. Refere-se à chegada ao Rio de Janeiro de Jerônimo, que veio denunciar essa situação e cobrar dos ministros da Agricultura e Trabalho o cumprimento do amparo prometido. Na matéria, é sugerido que Jerônimo teve dificuldades em encontrar os dois ministros e o tom assumido por Morel é de denúncia e apelo. Ainda dessa vez, é denunciada a exploração sofrida pelos jangadeiros por parte dos donos de embarcações e dos atravessadores que operam na beira-mar sem qualquer fiscalização. Cita dados que atestam que, dos 1.200 jangadeiros que residem entre o Mucuripe e a Volta da Jurema, cerca de $3 \mathrm{~km}$ de praia, apenas 23 são donos das embarcações que pescam. Pela reportagem de Morel, ficamos sabendo que a sugestão feita pelo titular da Delegacia de Caça e Pesca no Ceará, de que Jerônimo estava "mal instruído", e a defesa do pescador de que "não tem tempo para política", na verdade se referiam a boatos de que a "Associação Profissional do Ceará", criada por Jerônimo, era de orientação comunista.

É sabido que, no governo Dutra (1946-1950), como parte do alinhamento do país aos Estados Unidos e o posicionamento a favor da Guerra Fria, se deu uma ferrenha perseguição aos comunistas, sendo o PCB colocado na ilegalidade já em 1947. Ao mesmo tempo em que Jerônimo e seus companheiros ensaiavam formas organizacionais para lutarem por seus direitos, foram por alguns identificados como esquerdistas e mesmo como comunistas, sofrendo a Associação Profissional dos Pescadores perseguição e represálias por essa identificação, a exemplo do que ocorreu com a invasão e quebra de móveis da entidade, denunciada por Morel nessa reportagem do Última Hora: “É o velho processo já desmoralizado e que ainda surte efeitos", finaliza o jornalista.

Ilustrando essas reportagens, Morel dispôs flagrantes fotográficos que testemunham a dureza do trabalho no mar, a transação comercial que se verifica na beira-mar, "o momento preciso do assalto", como sugeriu no texto, e ainda as palhoças onde moravam os pescadores, que dão prova da miséria material em que viviam. Na legenda dessa última imagem, o jornalista anotou: "A paisagem é bonita e inspiradora, mas quem mora na palhoça vive na mais extrema miséria. Assim vivem os jangadeiros".

Em 20 de julho, retornando do Rio de Janeiro, Jerônimo vai novamente

criar os irmãos. Dona Josefina, contam as filhas, passou a ir para a beira-mar de Iracema todas as tardes, esperar que o mar devolvesse o corpo do marido.

35 Nesse período, os pescadores e suas entidades representativas se subordinavam ao Ministério da Agricultura.

36 Jornal Unitário, Fortaleza, 26 de abril de 1951, pp. 5-6.

37 Jornal Última Hora, Rio de Janeiro, 3 de julho de 1951, p. 12. O título dessa reportagem é: Vinte mil jangadeiros atirados à Miséria. Esse jornalista cobriu o primeiro raid e se aproximou muito dos jangadeiros, tendo assessorado Orson Welles na realização das filmagens de It's All True. 
até a redação do jornal Unitário, em Fortaleza, conversar com os jornalistas e prestar conta das conquistas resultantes de sua estada naquela cidade. ${ }^{38}$ Discorre novamente com os jornalistas sobre a miséria a que estavam submetidos e afirma desapontado: "É uma vida desgraçada essa nossa, tão desgraçada que parece que as autoridades têm medo de olhar para ela cara a cara”. Atesta, ainda, que o presidente concordou em substituir o delegado de Caça e Pesca do Ceará e que autorizou os pescadores a elegerem alguém identificado com suas causas. ${ }^{39} \mathrm{Na}$ ocasião, Jerônimo volta a falar do fantasma da caridade que teimava em perseguir os jangadeiros quando informa ao jornalista que tiveram de pedir esmolas para enterrar um companheiro morto, o jangadeiro Laurentino.

Em setembro, chega à capital federal uma comissão de pescadores a fim de informar ao presidente o nome do escolhido para substituir Sebastião Ramos. A audiência do presidente com os jangadeiros serve ao jornalista do Última Hora de exemplo para demonstrar o tom de informalidade e franqueza com que se davam as relações, naquele momento, entre a autoridade máxima do país e os trabalhadores. ${ }^{40} \mathrm{Na}$ ocasião, um dos jangadeiros presentes falou ao presidente:

Dr. Getúlio, nós estamos aqui para pedir justiça ao senhor. Os jangadeiros do Ceará estão abandonados, sofrendo toda sorte de privações. Além do mais estamos sendo miseravelmente roubados. O representante do governo lá é um verdadeiro ladrão.

A coluna "O Dia do Presidente" serve de reforço para a construção da imagem de Vargas como radicalmente diferente dos outros políticos mais distantes do povo, contribuindo assim para o "reforço do carisma" do presidente, tarefa que, segundo Negro e Teixeira, se incumbiram os trabalhistas da década de 1950. Mais uma vez, enxergo aqui uma "via de mão dupla" na relação dos trabalhadores com o Estado, pois, se o getulismo tira dividendos políticos dessa ação direta e espontânea dos pescadores, também os jangadeiros encontram um espaço para fazer ecoar seus gritos de denúncia e reivindicação. Vargas mais uma vez promete aos jangadeiros que o tal sujeito será afastado do cargo e que estes poderiam escolher alguém mais identificado com os interesses da categoria. ${ }^{41}$

\section{As viagens dos anos de 1950: ainda em águas do trabalhismo}

A promessa de Getúlio não se concretiza e os jangadeiros do Ceará resolvem que mais uma vez lançarão aos mares do getulismo uma jangada cabocla. Dessa vez é a Nossa Senhora de Assunção, que, com a liderança técnica e política de mestre

38 Jornal Unitário, Fortaleza, 20 de julho de 1951, p. 1.

39 Em 24 de julho de 1951, na última página, o jornal Unitário, de Fortaleza, divulga que Jerônimo José Severiano da Silva e Antônio Ribeiro de Lima, em comissão, foram à redação comunicar a escolha do nome de José Pinto Pereira para a Delegacia de Caça e Pesca do Ceará. Também informam que pediriam ao governador do Estado passagens para irem até Vargas levando um "extenso abaixo-assinado, dos Arpoadores até o Mucuripe".

40 Jornal Última Hora, Rio de janeiro, 17 de setembro de 1951, p. 3.

41 Em 06 de outubro de 1951, o jornal Unitário publica um telegrama enviado pelo então presidente da Associação dos Pescadores Profissionais do Ceará, José Antônio Ferreira, cobrando do presidente da República a pronta execução da promessa de substituir o tal Sebastião Ramos que, segundo o telegrama, vinha se estendendo desde julho daquele ano. 
Jerônimo, então já com 49 anos, levará até o Rio Grande do Sul, extremo do Brasil, na terra do presidente, memoriais a serem entregues ao próprio presidente, na passagem pelo Rio de Janeiro, e a Ernesto Dorneles, governador daquele estado e primo de Getúlio Vargas. Os companheiros de Jerônimo nessa nova viagem foram o experiente e sexagenário Tatá, Mané Preto, com a mesma idade de Jerônimo, companheiros da São Pedro, João Batista, sobrinho de Jerônimo, na época com 30 anos, e Mané Frade, pai de 23 filhos, dos quais doze, segundo frisa o jornalista, "conseguiram escapar do extermínio a que estão fadados os filhos dos pescadores". Frade, acrescenta a matéria, ${ }^{42}$ era "abatido fisicamente, mas de grande resistência". Sobre o objetivo da nova viagem, esclareceu Jerônimo: "Nosso raid ao Rio Grande do Sul será apenas para cobrar as promessas feitas e essa cobrança só poderá ser feita de corpo-presente, como vamos fazer".

No planejamento da viagem, os jangadeiros tinham como certo que iriam em alto-mar até Pernambuco, pela costa até o Rio de Janeiro, mas o trecho até Porto Alegre era inteiramente desconhecido, apesar da Capitania dos Portos ter fornecido aos pescadores uma lista de todos os faróis da costa brasileira. A jangada, de piúba como a São Pedro, era grande e veloz e foi feita por "QuintaFeira", "um dos melhores fazedores de jangada de nossas praias", acrescenta Jerônimo à reportagem do Unitário, publicada no dia 14 de outubro, dia da partida de Fortaleza.

Os preparativos da viagem foram bem diferentes do ocorrido em 1941. Nada de espetáculo da caridade pública e de padrinhos. O jornal Unitário, de 16 de setembro, fala de um "movimento popular para angariar fundos para a viagem", mas nada que se comparasse à campanha daqueles idos. Partiram de Fortaleza em 14 de outubro e, enquanto transcorria a viagem, jornais de várias partes do país divulgavam notícias da "façanha", numa demonstração de que a estratégia de visibilidade almejada pelos jangadeiros ainda era acertada. No Rio de Janeiro, onde uma recepção estava sendo organizada pela colônia cearense, o jornal Diário da Noite começava a preparar o espírito dos cariocas para a chegada dos jangadeiros do Ceará. Sobre a partida, diz a nota transmitida pela Agência Meridional:

Às 10:3oh de hoje, da praia do Náutico, partiram os jangadeiros que vão realizar o raid Fortaleza-Porto Alegre. Milhares de pessoas assistiram a largada da afoita jangada que leva em sua vela uma imagem pintada de Nossa Senhora, obra do pintor cearense Antônio Bandeira, recentemente chegado de Paris. Centenas de outras jangadas escoltaram até fora da barra a jangada Nossa Senhora de Assunção, na qual viajam companheiros do saudoso Jacaré, do raid Fortaleza-Rio de Janeiro. Os jangadeiros esperam chegar ao Rio em 45 dias. ${ }^{43}$

Enquanto os jangadeiros enfrentam o mar, ao longo do percurso de Fortaleza ao Rio de Janeiro, o jangadeiro José Pinto Pereira, na capital da República, tenta adiantar algum entendimento com autoridades do Estado e, desapontado, aproveita um dia em que Vargas atende um grupo de estivadores e trava com o presidente o seguinte diálogo, publicado no jornal última Hora: ${ }^{44}$

— Você ainda está por aqui? Então, o que já resolveu? Indagou o presidente.

42 Jornal Unitário, Fortaleza, 14 de outubro de 1951, p. 1.

43 Jornal Diário da Noite, Rio de Janeiro, 12 de outubro de 1951, p. 6.

44 Jornal Última Hora, Rio de Janeiro, 8 de novembro de 1951, p. 3; jornal Unitário, Fortaleza, 13 de Novembro de 1951, p. 1. 
— Pois é, presidente, a verdade é que ainda estou esperando. Já estive mais de dez vezes no Ministério e ainda não pude falar com o ministro. O meu dinheiro está acabando e eu acho que vou embora, esclareceu o jangadeiro.

Vargas manda interromper por algum tempo a audiência com os estivadores, manda chamar seu secretário particular e pede providências urgentes acerca das dificuldades comentadas pelo pescador.

José Pinto parece ter sido uma liderança importante entre os jangadeiros cearenses nesse período, mas nunca participou de uma viagem de jangada. Em outubro de 1951, ${ }^{45}$ um grupo de pescadores foi à redação do jornal Unitário para desmentir um boato de que esse pescador, escolhido entre eles para o posto de agente de pesca da Delegacia de Caça e Pesca local, tivesse envolvimento com os comunistas. Em uma época em que trabalhistas e comunistas disputavam a direção do movimento dos trabalhadores e o Partido Comunista se encontrava novamente na ilegalidade. Esse boato procurava descredenciar a ação reivindicatória de José Pinto, enquadrando-a no tipo de militância não aceitável e não apoiada pelo Estado, expressa nas palavras dos pescadores que foram à redação do Unitário: "Trata-se de uma exploração (...) a fim de incompatibilizar os pescadores com as altas autoridades do país".

Como sugerem Negro e Teixeira, ${ }^{46}$ apesar do retorno de Vargas ter se dado em um ambiente democrático, diferente da ditadura do Estado Novo que o sustentou no primeiro momento, os sindicatos continuaram sendo fortemente controlados pelo Ministério do Trabalho. Ainda sem uma estrutura sindical nos moldes dos trabalhadores urbanos das indústrias, os pescadores do Ceará ensaiavam formas de se inserir na esfera do Estado, correspondendo à forma direta posta em prática pelo presidente, num movimento de reforço da figura pessoal de Vargas, independente até da ação de seu ministério, pois, conforme publica o jornal última Hora:

José Pinto, humilde trabalhador cearense, ainda não conseguiu realmente falar com o ministro, mas, em compensação, pode orgulharse de uma cousa: o Sr. Getúlio Vargas, presidente da República, já recebeu três vezes o modesto pescador em menos de vinte dias. ${ }^{47}$

Se José Pinto enfrentava a burocracia do Estado Varguista em terra, Jerônimo e seus companheiros, no mar, conseguiram vencer as ondas e o tempo ruim até o Rio de Janeiro, em 63 dias. Os jangadeiros foram dados por desaparecidos duas vezes ao longo da viagem, após a saída do Rio Grande do Norte e antes da chegada em Vitória, Espírito Santo. Enfrentaram o extravio de uma peça da jangada, uma tranca, que foi enviada de Fortaleza por avião e entregue em Vitória. Chegando à capital do Espírito Santo, são e salvo, Jerônimo fica sabendo que havia sido despejado da "choça" onde morava, através de uma ordem judicial, caso que parece ter sido levado ao presidente. ${ }^{48} \mathrm{Em} 13$ de dezembro, os jangadeiros chegam ao Rio de Janeiro, após enfrentarem temporais, mar "encapelado" e trazendo a bordo um filhote de baleia e um peixe até então desconhecido, pescados no caminho, sendo saudados pelos cariocas com entusiasmo na praia de Copacabana, como na filmagem de Orson Welles, de 1942.

45 Jornal Unitário, Fortaleza, 19 de outubro de 1951, p. 2.

46 SILVA, Fernando Teixeira da; NEGRO, Antônio Luigi. "Trabalhadores, sindicatos e política (1945-1964)". In: FERREIRA, Jorge; DELGADO, Lucília de Almeida Neves (orgs.). O Brasil Republicano: o tempo da experiência democrática. Rio de Janeiro: Editora Civilização Brasileira, 2003.

47 Cf. jornal Unitário, Fortaleza, 13 de novembro de 1951.

48 Jornal Unitário, Fortaleza, 21 de dezembro de 1951, p. 5. 
No Rio de Janeiro, os jangadeiros encontraram o presidente em uma audiência privada, bem diferente do que aconteceu em 15 de novembro de 1941, quando Vargas mandou abrir os portões do Palácio Guanabara, permitindo que os populares participassem daquela reunião pública entre o presidente da República e quatro pobres trabalhadores. A conversa no gabinete presidencial demorou, segundo o jornalista, ${ }^{49}$ uma hora, tempo em que os jangadeiros entregaram o memorial a Vargas.

Nas imagens abaixo temos alguns registros das viagens de 1941 e 1951. Na primeira sobressai a ênfase na conversa direta entre Vargas e Jacaré, o chefe do governo e o chefe dos jangadeiros, segundo frisa o jornal A Manhã, do Rio de Janeiro. Na segunda, o foco está no documento entregue pelos jangadeiros a Vargas, cobrando as promessas feitas. Nas duas, o encontro entre o presidente e os trabalhadores, sem mediações, como pregava o trabalhismo.

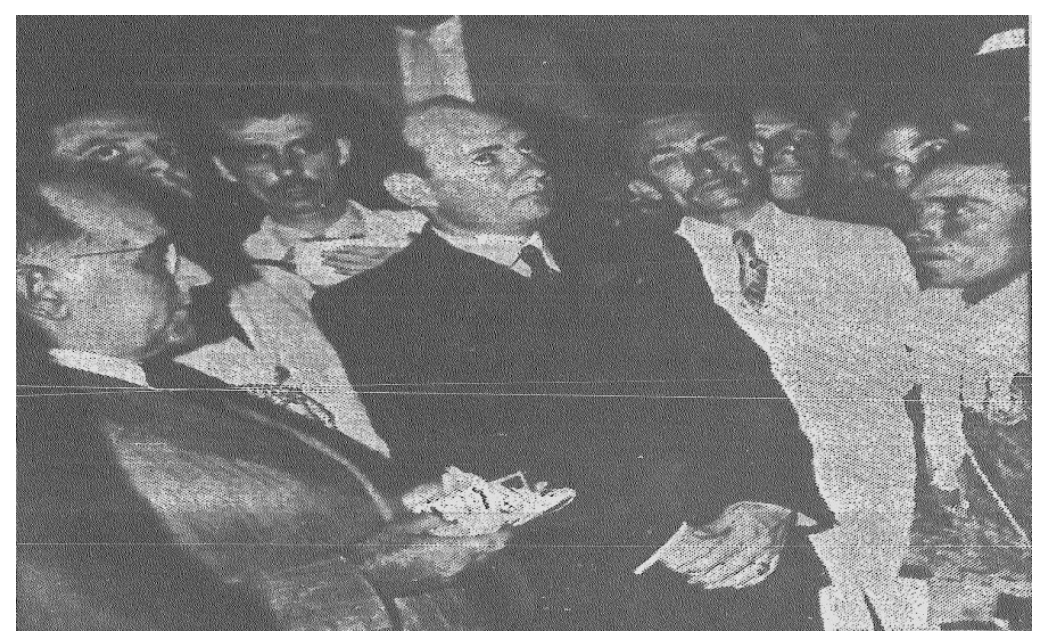

Fonte: jornal A Manhã, nov./1941.

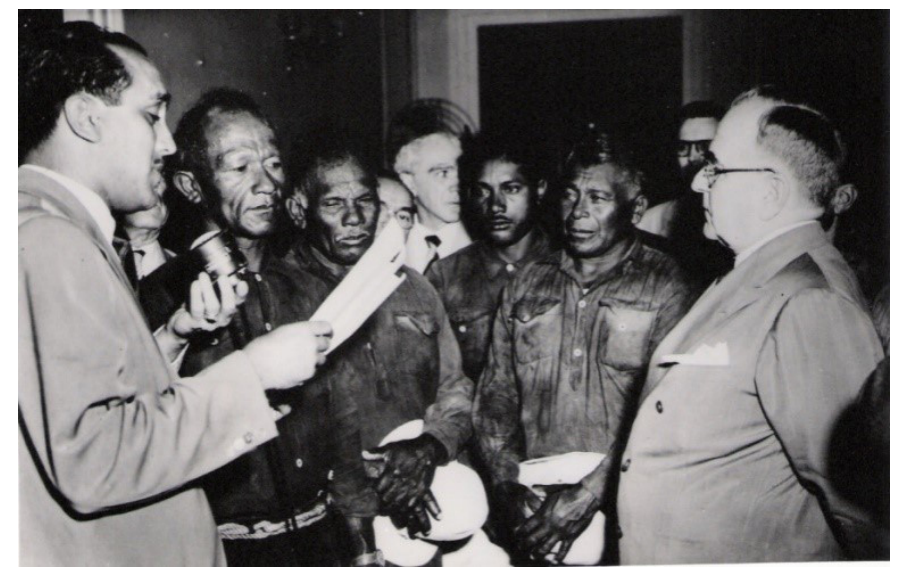

Fonte: Arquivo Nacional.

Enquanto os jangadeiros cumpriam uma agenda de entendimentos no Rio de Janeiro, dentre eles um encontro com o ministro da Marinha, a quem também levaram reivindicações, Tatá, o velho pescador da praia de Iracema, caiu doente de malária, sendo examinado e acompanhado por Mário Pinotti, diretor do Departamento Nacional de Malária, ${ }^{50}$ e ficou retido no Rio, internado em uma hospital da cidade. Por essa mesma época, o almirante da Marinha, Frederico

49 Jornal Unitário, Fortaleza, 18 de dezembro de 1951, última página.

50 Jornal Unitário, Fortaleza, 25 de dezembro de 1951, p. 1. 
Vilar, aquele mesmo que, no cruzador José Bonifácio, percorreu a costa brasileira organizando em colônias os pescadores que nela habitavam e trabalhavam, faz um apelo ao presidente para impedir o prosseguimento do raid de Jerônimo e seus companheiros. Vilar argumentava, com conhecimento de causa, que era uma viagem muito arriscada para tão frágil embarcação. Nos trechos de maior perigo, dentre eles aquele que vai de Santa Catarina ao Rio Grande, ele alerta:

Até navios têm por ali desaparecido sem que se saiba o que lhes ocorreu. É muita temeridade enfrentar esses mares do sul com uma jangada. $\mathrm{E}$ essas vidas são preciosas. São valentes brasileiros, pescadores que bem representam o espírito de arrojo e de patriotismo de tal classe. ${ }^{11}$

Apesar dos apelos do almirante, os jangadeiros prosseguiram a viagem; suas recomendações, entretanto, de que fossem dadas orientações por técnicos em navegação, parece ter sido acatada. ${ }^{52}$ De fato, os pescadores do Ceará enfrentaram "fortes rajadas de vento e mar encapelado" no trecho de Santos a Paranaguá. De Curitiba a Florianópolis tiveram que vencer uma tempestade por 24 horas, quando a jangada foi "batida por forte aguaceiro e ventania", segundo noticia o Unitário, de 2 de fevereiro de 1952. Enquanto enfrentavam a fúria do mar rumo ao destino almejado, alguns pescadores de Alagoas chegam ao Rio de Janeiro em uma embarcação, "menor que a de Jerônimo", mas, segundo enfatiza o jornalista, "não haviam ido à capital da República buscar louros e glórias, mas sim, trabalho".

Em 18 de fevereiro, os jangadeiros chegaram a Porto Alegre e, na praia das Belas, foi montado um palanque oficial, onde discursaram Ernesto Dorneles, governador do Rio Grande do Sul, e Ildo Meneghetti, prefeito de Porto Alegre. A jangada, ornada com três bandeiras, do Brasil, do Ceará e do Rio Grande do Sul, ficou exposta na Praça Xavier Ferreira e depois foi doada ao Museu Júlio de Castilhos. No Rio Grande do Sul, além das solenidades e visitas em Porto Alegre, os jangadeiros seguiram para visitar cidades do interior do estado, participando de um churrasco na fazenda Itu, de propriedade de Vargas. Retornam ao Rio de Janeiro, parando em Santos para receberem aulas práticas de pesca "em moderno navio a vapor", ${ }^{53}$ para depois encontrarem Tatá e retornarem ao Ceará a bordo de um avião da Cruzeiro do Sul.

\section{O saldo das "viagens" de Jerônimo e seus companheiros: o protagonismo}

Ao longo da travessia Fortaleza-Rio Grande do Sul, os jangadeiros conseguiram impressionar a sociedade e as autoridades do país para a situação em que se encontravam e assim justificavam suas ações de reivindicação e amparo estatal. Há que se destacar na luta desses jangadeiros dos anos de 1950 o protagonismo de suas ações. Insisto que eles tomaram para si, com os erros e acertos não previsíveis, a direção das suas ações. Não esperaram de partidos ou de representantes de outros meios a verbalização de suas reivindicações, mas acreditaram, inclusive através do aprendizado da luta nos anos de 1940, que só eles

51 Jornal Unitário, Fortaleza, 08 de janeiro de 1952, p. 1.

52 Jornal Unitário, Fortaleza, 29 de dezembro de 1951, p. 1.

53 Jornal Unitário, Fortaleza, 18 de março de 1952, p. 8. 
poderiam estar na frente da luta, a seu modo. Mas há que reconhecer a confiança depositada ao longo desses anos naqueles que Jacaré denominou "os amigos de todos os tempos", o pessoal da imprensa.

Essa é outra conclusão a se chegar: o importante papel de setores da imprensa na sensibilização da sociedade para a causa desses populares. Eles operavam, nas várias reportagens que fizeram exaustivamente ao longo dos anos de 1940 e 1950, uma exposição detalhada daquilo que demonstravam ser o drama vivido pelos pobres pescadores, tomando partido de suas causas e clamando por justiça social. E, deve-se assinalar, diferente do que vai ocorrer nos dias de hoje, são os pescadores que procuram, na maioria das vezes, a imprensa e a visibilidade que ela proporciona. Estar entre os jornalistas, garantir suas adesões, e ver divulgada a questão que, no momento, afeta os pescadores, a morte de um pescador no mar e o desamparo de famílias, o mau desempenho de um titular da administração da pesca, o não cumprimento de uma ordem legal ou de uma promessa feita, enfim, é parte do projeto colocado em prática pelos pescadores.

Mas há que se considerar, ainda, que parte dessa cultura política dos pescadores e, especialmente, daquela experimentada por mestre Jerônimo, está fincada na crença no Estado como uma via capaz de livrar os homens pobres como ele, das "grades da vida em terra firme", ou seja, da caridade pública e da esmola. Desde os anos de 1930, os jangadeiros elaboram uma pauta de demandas que, muitas vezes, extrapola a esfera daquilo que está enquadrado na ação estatal em forma de políticas públicas e direitos sociais. Refiro-me particularmente a uma denúncia que vem se arrastando secularmente no cotidiano do trabalho da pesca artesanal, desde Jacaré até os pescadores dos dias de hoje: o fato de que muitos pescadores não sejam proprietários dos instrumentos de trabalho, especialmente da jangada (ou bote etc.), tendo que se sujeitar à vontade de patrões e atravessadores (comerciantes de pescado).

Mas, em vez dos dirigentes da pesca ouvirem os brados de Jacaré, assumidos por Jerônimo e outros companheiros, no sentido de ampliar a ação intervencionista do Estado no universo das relações de trabalho na pesca, o Estado trabalhista, fincado numa certa visão do desenvolvimento nacional, resolveu apostar na modernização da pesca, o que implicava a busca de maior produtividade, investindo na modernização da frota pesqueira e em investimentos na pesca empresarial, já nos anos de 1960, assunto ricamente discutido pelo antropólogo Antônio Carlos Diegues. ${ }^{54}$

Nos dois períodos de Vargas, o empenho das autoridades governamentais será no sentido de conseguir enquadrar efetivamente os pescadores na legislação trabalhista, meta jamais alcançada, pois essa legislação não poderia abarcar relações de trabalho informais como aquelas vividas pelos jangadeiros. Mas, o certo é que, apesar dos limites dos ganhos materiais, os ganhos simbólicos e o aprendizado do protagonismo da luta por direitos, assumidos desde os anos de 1930 pelos pescadores, alimentaram nos jangadeiros, especialmente em Jerônimo, a crença no Estado e, particularmente, naqueles que, no contexto referido, assumiam mais diretamente o discurso das leis sociais, os trabalhistas.

Quero me arriscar a interpretar que essa relação foi fortemente alimentada e vai ao encontro da cultura política própria do trabalhismo ${ }^{55}$ e de sua ênfase na questão social e nos direitos sociais. Ora, o encontro alimentado por um opositor

54 DIEGUES, Antônio Carlos. Pescadores, Camponeses e Trabalhadores do Mar. São Paulo: Ática, 1983.

55 GOMES, Ângela de Castro. A Invenção do Trabalhismo. Rio de Janeiro: IUPERJ/Vértice, 1988; FERREIRA, Jorge. O Imaginário Trabalhista. Rio de Janeiro: Civilização Brasileira, 2005. 
do varguismo, Carlos Lacerda, com o presidente Eurico Dutra, não teve grandes desdobramentos para a luta dos pescadores, mas os entendimentos com Vargas e os desentendimentos com alguns de seus ministros provocaram muitos desdobramentos e até uma nova e arriscada viagem, até a terra do presidente, São Borja, num movimento simbólico de participação da onda nacionalista alimentada pelos trabalhistas nos anos de 1950, unindo e aproximando, pelo litoral, o "norte" e o "sul".

Estou experimentando denominar esse comportamento político dos jangadeiros como uma cultura política, pois entendo que estou tratando das "concepções, lógicas cognitivas, vivências e sensibilidades" de atores coletivos ou individuais. Analisando a ação desses sujeitos desde os anos de 1930, entendo que, nessa média duração, reclamada por esse conceito, como lembra Ângela de Castro Gomes, já é possível perceber certos padrões de comportamento, sem, contudo, descuidar de atentar para os movimentos e as transformações, como também adverte a autora. ${ }^{56}$

A fibra, a coragem e o destemor desses trabalhadores foram comprovados, mais uma vez, por ocasião da viagem de jangada em 1951/1952. Foram destaque nos principais jornais do país e receberam presentes - vinhos do sul, chapéus Ramenzon, camisas Banton, atendimento médico especializado, aulas práticas da pescaria moderna, além da doação em dinheiro, como aqueles 40 mil cruzeiros da prefeitura de Porto Alegre. ${ }^{57}$

Jerônimo, sendo entrevistado logo ao chegar ao Rio Grande do Sul, disse inicialmente aos jornalistas que "estava tão cansado, tão cansado, que mal podia falar". Mas, instado a falar sobre seu sentimento ao cumprir tão arriscada travessia, disse que "esperava que o feito dos jangadeiros que chegava ao fim naquele instante não ficasse apenas como um ato de bravura dos cinco, mas que servisse para elevar bem alto as reivindicações dos homens do mar do Nordeste brasileiro, que há anos esperam uma solução para os seus problemas". Ao saber da verba a ser dada a cada jangadeiro, votada na assembleia gaúcha, Jerônimo, que procurava fugir da prática da caridade pública que insistia em segui-lo, aprisionando-o nas "grades da vida em terra", disse melancólico ao jornalista: "A finalidade da viagem, a obtenção de melhores dias para a laboriosa classe, ainda não foi alcançada". ${ }^{8}$

Durante toda a década de 1950, a luta de Jerônimo prossegue e o tempo da política acaba assumindo um lugar maior em sua vida. As estratégias utilizadas se repetem, crescendo a crença no sindicato como a instância capaz de garantir o cumprimento dos direitos sociais prometidos.

56 Sobre o debate acerca da utilização do conceito de cultura política: KUSCHNIR, Karina; CARNEIRO, Leandro Piquet. "As dimensões subjetivas da política: cultura política e antropologia da política”. Estudos Históricos. Rio de Janeiro: CPDOC/Fundação Getúlio Vargas, v.13, n.24, 1999, pp. 227-250; GOMES, Ângela de Castro. "Cultura política e cultura histórica no Estado Novo". In: ABREU, Martha; SOIHET, Rachel; GONTIJO, Rebeca. Cultura política e leituras do passado: historiografia e ensino de história. Rio de Janeiro: Civilização Brasileira, 2007, pp. 43-63; GOMES, Ângela de Castro. "História, historiografia e cultura política no Brasil: algumas reflexões". In: SOIHET, Rachel; BICALHO, Maria Fernanda Baptista; GOUVÊA, Maria de Fátima. Culturas políticas: ensaio de história cultural, história política e ensino de história. Rio de Janeiro: Mauad, 2005, pp. 21-44.

57 Jornal Unitário, Fortaleza, 18 de dezembro de 1953, p. 6.

58 Jornal Unitário, Fortaleza, 19 de fevereiro de 1952, p. 6. 


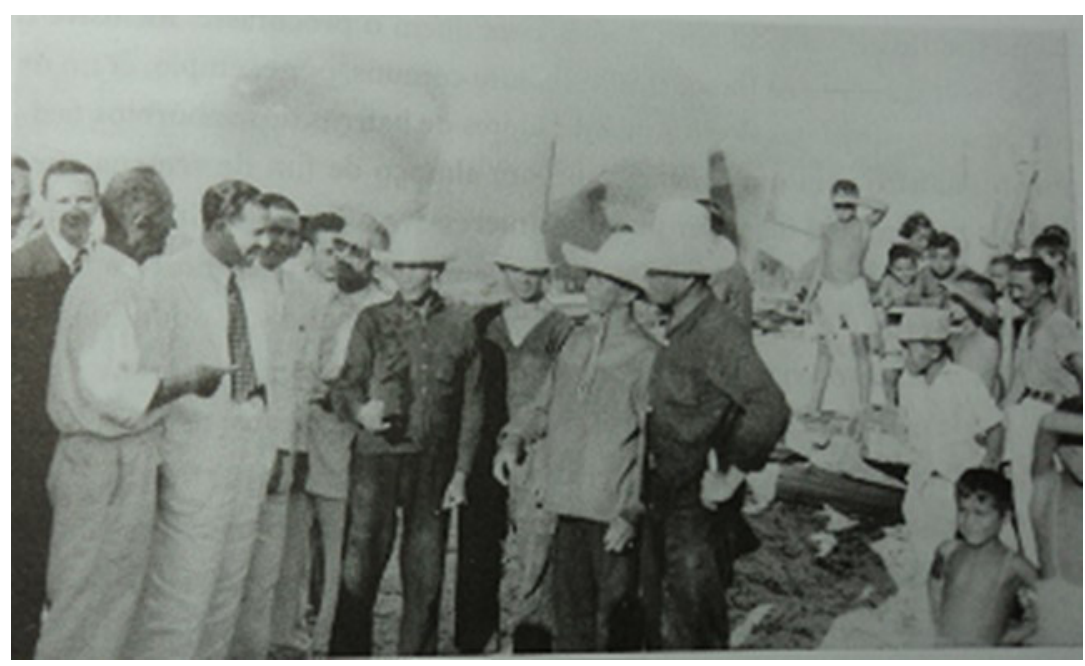

Na imagem acima, de 1953, extraída do cinejornal Roteiro da Redenção do trabalhador brasileiro: conhecendo de perto as reivindicações dos trabalhadores, ${ }^{59}$ mestre Jerônimo aparece gesticulando, em frente aos companheiros de trabalho e ao lado de Goulart, estando o mestre e o então ministro do Trabalho, Indústria e Comércio do governo Vargas com roupas claras, diferente dos demais pescadores que aparecem vestidos de roupas de trabalho.

Nesse contexto, Goulart percorria o Norte e Nordeste do país, com o objetivo de conhecer a realidade dos trabalhadores dessas regiões. Tem início aí uma relação que se estenderá ainda por muitos anos, selada com a homenagem que o mestre fará ao vice-presidente do governo Kubitschek, já em 1958, quando batizará a jangada que singrará os mares do Brasil até a Bacia do Prata, a cidade de Buenos Aires, de "Maria Tereza Goulart".

Leio as ações desses sujeitos e qualifico-as como "ações sociais e políticas" porque considero que, cercados por condicionamentos sociais, políticos, econômicos e culturais, esses sujeitos operam escolhas e orientam suas ações a partir delas, "como resultado de uma constante negociação, manipulação, escolhas e decisões do indivíduo, diante de uma realidade normativa que, embora difusa, não obstante oferece muitas possibilidades de interpretação e liberdades pessoais", como sugere Giovanni Levi. ${ }^{60}$

A ação política dos jangadeiros, realizada na década de 1950, seja através do recurso à imprensa para expor suas mazelas e convencer a sociedade civil da legitimidade de suas lutas, ou na tentativa de constituição de um sindicato, ou, ainda, na busca por relações pessoais com presidentes da República e outras autoridades políticas, se aproxima de outras experiências de trabalhadores brasileiros urbanos no mesmo contexto.

Deslocando a abordagem de uma ênfase no Estado e sua capacidade de "dominação", vários estudos historiográficos, estimulados pelas abordagens da história social inglesa, em especial das contribuições de E. P. Thompson, se voltaram para a ação social desses sujeitos e enxergaram o populismo não como um "fechado e acabado sistema de dominação, mas como um aberto e indeterminado jogo político que implicava barganhas políticas e evidentes conquistas de direitos", como sintetizou Fernando Teixeira, em um balanço das abordagens sobre a questão

59 Cinejornal informativo n 13/53 - Edição Especial (1953). http://www.zappiens.br:8o/videos/cgiR-2gjeEaf-jNyGo7HwmnHj5C17nbQER6YjkoedscSIA.FLV.

60 LEVI, Giovanni. "Sobre a micro-história”. In: BURKE, Peter (Org.). A Escrita da História. São Paulo: UNESP, 1992. 
das ações e lutas dos trabalhadores no contexto daquilo que se convencionou chamar na historiografia brasileira de "período populista", que se estende das décadas de 1930 à de $1960 .^{61}$

É nessa mesma perspectiva que os vários estudos reunidos na obra Na luta por direitos: estudos recentes em História Social do trabalho, analisam experiências de trabalhadores em Porto Alegre, São Paulo e Rio de Janeiro, recuperando formas de ação política e estratégias de lutas que se distanciam daquela visão consagrada por certa historiografia que ocultou ou minimizou essas ações por maximizar o papel do Estado. ${ }^{62}$

As análises de Ângela de Castro Gomes, especialmente em A Invenção do Trabalhismo, e de Jorge Ferreira, em Trabalhadores do Brasil e O Imaginário Trabalhista, fornecem importantes pistas para a compreensão das motivações que levaram trabalhadores brasileiros a se inserirem na política lutando por direitos sociais e fazendo coincidir suas aspirações com as propostas de autoridades trabalhistas, a exemplo de Getúlio Vargas e João Goulart. ${ }^{63}$

Jangadeiros, imprensa, Vargas, Jango, direitos, sindicato, viagens reivindicatórias. Estes termos interligados neste artigo quiseram sugerir uma determinada forma de ação política de sujeitos sociais, diferente do enfoque dado pela literatura, pintura, fotografia e ainda pelos estudos folclóricos. ${ }^{64}$ Ele tratou da emergência política desses sujeitos, informados por uma determinada cultura política.

61 SILVA, Fernando Teixeira da; COSTA, Hélio da. "Trabalhadores urbanos e populismo: um balanço dos estudos recentes". In: FERREIRA, Jorge. O populismo e sua história: debate e crítica. Rio de Janeiro: Civilização Brasileira, 2001.

62 Conferir a esse respeito: FORTES, Alexandre e outros. Na luta por direitos. Campinas: Editora da UNICAMP, 1999.

63 GOMES. A Invenção do Trabalhismo; FERREIRA. O Imaginário Trabalhista e FERREIRA, Jorge. Trabalhadores do Brasil. Rio de Janeiro: Ed. FGV, 1997.

64 A imagem de jangadeiros é fartamente explorada em várias linguagens artísticas em especial por sua beleza plástica e pela rusticidade de sua feição em relação à imensidão do oceano, seu locus de trabalho. Câmara Cascudo, dentre outros, enfocou os jangadeiros em perspectiva etnográfica em, pelo menos, dois estudos já citados: Jangadeiros e Jangadas. Entretanto quero sugerir que, nessas abordagens, não está tematizada a questão das lutas políticas travadas por esses trabalhadores. 